\title{
ÍDOLO-ESPÁTULA SOBRE RADIO HUMANO EN EL AJUAR DE UN SEPULCRO MEGALÍTICO DE LA MESETA ${ }^{1}$
}

\section{A SPATULA-IDOL ON HUMAN RADIUS IN A MEGALITHIC TOMB OF THE SPANISH CENTRAL PLATEAU}

por

\author{
GERMÁN DELIBES DE CASTRO \\ FELIX J. DE PAZ FERNÁNDEZ
}

\begin{abstract}
RESUMEN Se estudia un ídolo-espátula de hueso, sobre radio humano, que procede de una tumba colectiva neolítica de la provincia de Valladolid (España). Los autores formulan diversas hipótesis sobre su significado
\end{abstract}

ABSTRACT This paper studies the presence of a spatula, obtained from a human radius, in a neolithic tomb from Valladolid (Spain). The autors offer several hypothesis about its meaning

Palabras claves Ídolo-espátula, radio humano, osario colectivo, neolítico

Key words Idol, spatula, human radius, collective burial, neolithic

En los últimos años la saludable costumbre de estudiar los osarios dolménicos se ha traducido en un decidido incremento de la información sobre los rituales funerarios del IV y III milenio a.C. Como muestra de ello, parece superado el tópico de que el megalito fue una "tumba para todos" y se sabe que las inhumaciones se reclutaban selectivamente, afectando de manera desigual a los miembros de la sociedad según su sexo y edad. Además se ha avanzado no poco en la manida discusión de si los enterramientos fueron primarios o secundarios, comprobándose que, en la mayoría de los casos, el desorden de los calavernarios fue consecuencia de las reducciones de restos efectuadas a lo largo del tiempo para reorganizar el espacio. Y, cambiando un poco de perspectiva, también se ha tomado conciencia de la nada infrecuente ausencia en las sepulturas de determinados tramos esqueléticos, enigmáticamente sustraídos de los carneros por quienes oficiaban en ellos (Andrés 1998; Masset 1993).

1. Queremos mostrar nuestra gratitud a los Dres. Botella, Etxeberría y Velasco por las valiosas sugerencias que nos han hecho. 
Se van sentando las bases, en suma, para un mejor conocimiento del ritual y de la burocracia de la muerte de aquellos momentos, al tiempo que surgen y se formulan nuevas preguntas como las que nos llevan a interrogarnos por el paradero de los individuos excluidos total o parcialmente -en el primer caso como si no revistieran el estatus de difuntos-de la sepultura. Las sombras en este terreno siguen dominando a las luces, pero alguna incógnita se va despejando sobre el paradero de esos desplazados. La excavación de algunos hábitats que, por razones de espacialidad y temporalidad, se suponen complementarios de megalitos aledaños -el binomio poblado / sepulcro, vivos / muertos-, ha permitido, por ejemplo, constatar las acumulaciones de restos humanos en áreas domésticas lo que acaso esté relacionado con una "circulación de reliquias" entre los vivos, plena de sentido en el marco general de un culto a los antepasados (Bradley 1998: 62). También tenemos información sobre el trágico destino de otros hombres y mujeres del Neolítico nunca sepultados: los que, como en el caso bien estudiado de Fontbregoua, fueron objeto de canibalismo (Villa et alii 1986). Y hasta parece lícito plantearse si los restos de algunas de las personas que fueron vetadas en el sepulcro colectivo no pudieron acabar convirtiéndose, tras alguna modificación, en trofeos exhibidos por los supervivientes.

En el horizonte megalítico de la Submeseta Norte, como luego tendremos ocasión de comprobar, no faltan muestras de parecida complejidad funeraria y, en relación con ella, tenemos la intención de ocuparnos aquí del estudio de uno de estos posibles "trofeos" -instrumentos fabricados sobre huesos humanos-que formaba parte del ajuar de una tumba dolménica de Valladolid. Sirva ello de homenaje a ese gran prehistoriador que es Enrique Vallespí, cuya bonhomía, honradez y magisterio son un excelente ejemplo para quienes hemos de desenvolvernos en el nada sencillo mundo de la Arqueología del siglo XXI.

\section{Espátula tipo San Martín-EI Miradero, sobre radio humano, del sepulcro megalítico de Los Zumacales (Simancas)}

Es hallazgo realizado hace tres lustros en el transcurso de la excavación del osario de un peculiar megalito vallisoletano, que se caracteriza por disponer no de los normales ortostatos enhiestos delimitando una cámara, sino de grandes losas apaisadas que -por lo que creemos intuir en el monumento similar de La Velilla, en la provincia de Palencia (Delibes y Zapatero 1995)- pudieron servir de basamento a una pared de tapial muy probablemente pintada de rojo. En el interior de esta original construcción, de planta casi perfectamente circular y protegida por un túmulo asimismo redondo, alcanzó a rescatarse, en intervención de urgencia, un abigarrado calavernario con cerca de 1700 restos correspondientes al menos a dos docenas de individuos (Sampedro 1998) y, asociadas a él, un conjunto de ofrendas muy propias de cualquier yacimiento dolménico: hachas pulimentadas, láminas y trapecios tallados en sílex -los últimos con retoque abrupto-, cuentas de collar de distintos materiales y factura, unos posibles ídolos esféricos de piedra y un conjunto de instrumentos de hueso-punzones, colgantes-entre los que se cuentan la espátula que nos interesa y otra pieza comparable formal y decorativamente, pero trabajada sobre tibia de ovicaprino (Delibes et alii 1987).

En rigor, no se dispone de dataciones absolutas para este conjunto, pero sí para un enigmático depósito inmediatamente previo a la construcción. Localizado bajo el sector meridional del túmulo, reviste la forma de una bolsada de tierras blanquecinas, cenicientas, entre las que se mezclan abundantes cerámicas lisas, útiles líticos análogos a los documentados en el espacio propiamente funerario, y una modesta colección faunística (Santiago 1991), habiendo sido datado por el radiocarbono poco después del 5000 B.P. Unas fechas, por tanto, bastante acordes con las obtenidas para el mencionado yacimiento de La Velilla o para otro sepulcro vallisoletano, también colectivo, El Miradero en Villanueva de Los Caballeros, los cuales significativamente aportan ajuares casi idénticos al descrito (Delibes et alii 1986).

El objeto por el que nos interesamos responde con exactitud al esquema de ciertos ídolos-espátula, a los que se denomina de tipo San Martín-El Miradero por haber sido identificados originalmente en el nivel 
inferior de aquel dolmen alavés -en realidad el hallazgo de Gúrpide y otro posible de Pamplonagañe serían previos (Apellániz 1962; Barandiarán y Fernández 1964)-y, luego, mucho más profusamente en el yacimiento vallisoletano, los cuales se caracterizan por presentar un mango decorado en bulto redondo y una zona eficaz o pala, cuya anchura aumenta conforme se aproxima a su extremo distal (Mújika 1998). Roto y perdida buena parte del mango o fuste, mide actualmente $157 \mathrm{~mm}$ de longitud, 40 de ancho en el frente de la pala y 15 en el extremo opuesto. Quiere ello decir que de la pieza primitiva se conserva casi completa la espátula, pero sólo el arranque del mango -por cierto, con restos de ocre- lo que no es obstáculo para reconocer en él las huellas de una decoración estriada que, en la cara dorsal, se materializa en un motivo de ángulos similar al de otros ejemplares de los yacimientos epónimos.

Respecto al hueso aprovechado como soporte, es un radio derecho humano cuya cavidad medular (allí donde el tejido oseo se manifiesta más compacto) acoge la garganta de la espátula, mientras que su frente se adecua al extremo distal, más ancho, donde se han recortado las apófisis (en especial la estiloides, buscando cierta simetría) y, sobre todo, se ha efectuado un trabajo de adelgazamiento que ha tenido como consecuencia que aflore el tejido esponjoso, más blando y vulnerable, afectando a la conservación de este tramo. Como hemos tratado de subrayar gráficamente (fig. 1) al presentar los resultados de la fabricación experimental de un objeto similar al prehistórico, la identificación del hueso-soporte como un radio humano es incuestionable, lo cual no es óbice para llamar la atención sobre el posicionamiento muy distal del agujero nutricio.

\section{Ni todos los esqueletos ni todos los huesos: evidencias de enterramientos selectivos y de circulación de reliquias en la Submeseta Norte}

Si nos ceñimos a las tierras de la Meseta superior, sólo con reparar en la entidad de los osarios del sepulcro de corredor de Las Arnillas, en la Lora burgalesa (cerca de medio centenar de inhumaciones) o de La Velilla (aproximadamente el doble) se crea cierta predisposición a pensar que, durante el IV y el III milenio a.C., los restos esqueléticos de la mayoría de los difuntos estaban llamados a encontrar su destino definitivo en las cámaras de las sepulturas megalíticas. Mas un simple repaso de los despojos fúnebres colectados en el primero de tales yacimientos se encarga de demostrar que aquella no es una percepción acertada, pues se trata de un depósito asimétrico, que no responde a la composición de la población a la que representa: excluye prácticamente por completo, en efecto, a los niños y acoge a sólo una mujer adulta por cada tres varones (Delibes 1995: 76-79; ídem 1998).

Por ello es comprensible que la investigación se mantenga expectante ante otros posibles documentos arqueológicos -más allá de los propios dólmenes-que informen sobre cual pudo ser el destino de aquellos individuos no merecedores del póstumo reclutamiento megalítico. La hipótesis de que algunos de ellos pudieran haber sido víctimas de canibalismo, como antes señaláramos, no carece por completo de fundamento en la cuenca del Duero si se tiene en cuenta el hallazgo, todavía inédito, de distintos huesos humanos, nada raramente partidos, que formaban parte, junto con otros de bos, ovis y sus, de lo que parecía ser un muladar infrayacente al ya referido monumento megalítico de Los Zumacales en Simancas (Santiago 1991). La impresión es, como decimos, de un simple basurero en el que los huesos, animales y humanos, se mezclan con abundantes cerámicas rotas, con cenizas y con tierras ricas en materia orgánica; pero, habida cuenta su localización bajo el túmulo del sepulcro, tampoco nos atrevemos a descartar la posibilidad de un depósito ritual, del resultado de una auténtica suovetaurilia fundacional, a la que se hubieran agregado simbólicamente ciertos restos humanos de una tumba anterior con la idea de proyectar sobre la nueva la siempre benefactora sombra de los antepasados. Una forma de actuar no muy distinta, diríamos, de la que seguramente indujo a los constructores del gran sepulcro de corredor coruñés de Dombate a incorporar a la nueva y majestuosa cámara el osario de una pequeña mámoa previa, fosilizada por el más moderno monumento (Bello 1994). 
Otro testimonio meseteño de indudable interés a la hora de profundizar en la misma problemática es el cráneo humano, perfectamente conservado, que se descubriera bajo el suelo de una cabaña en el transcurso de las excavaciones efectuadas en el poblado de La Viña de Esteban García, en el valle medio del Tormes. Lo significativo en este caso es que el referido yacimiento es, con seguridad, el contrapunto habitacional de un conjunto de monumentos megalíticos ubicados a su alrededor-Prado Nuevo y Prado de la Nava, en Salvatierra, y El Teriñuelo, en Aldeavieja-, en los que no cabe ver sino sus cementerios. Así las cosas, no habría que descartar que la susodicha calavera fuera un desecho doméstico más, entre los muchos registrados en el hábitat. Pero la doble circunstancia de ser el único resto humano detectado y de tratarse de una calota craneana, esto es de una pieza esquelética de evidente significado simbólico, nos llevan a decantarnos por la opción de unos "muertos en movimiento", en la línea de lo defendido por Cauwe (1997), y a considerar se trata de un resto extraído del osario para ser trasladado como reliquia al ámbito habitacional. Quién sabe, incluso, si al hogar se sus deudos más próximos (Delibes et alii 1997: 788-802). He ahí, por tanto, otro posible destino de algunos de los huesos sustraídos de los calavernarios, sobre todo de los calavernarios recogidos en el interior de tumbas megalíticas abiertas -los pasillos de los sepulcros de corredor, además de facilitar futuras inhumaciones, propician el contacto físico con los restos de los inhumados o, como dice el mencionado Cauwe (1998: 452), "mientras la tumba individual asegura la integridad de los esqueletos, la colectiva, abierta, fomenta las manipulaciones postinhumatorias"-, y, muy probablemente también, de aquellos otros, asimismo colectivos, que hallan acomodo en el interior de cuevas (Delibes et alii 1999).

En el caso de la reliquia aislada que ahora presentamos -junto a la pieza de Los Zumacales seguramente tendría cabida un puñal del sepulcro de corredor de Las Arnillas, que se sospecha sobre tibia humana (Delibes et alii 1986), pero no así un diente del megalito asimismo burgalés de La Cabaña, en Sargentes de La Lora, pues su perforación parece consecuencia de una caries-podríamos encontrarnos también ante uno de esos huesos retirados ritualmente de los calavernarios, por más que luego regresaran a ellos bajo la forma de ofrendas. Sin embargo, reviste la particularidad de ser hueso humano manipulado y trabajado, por lo que entra ya en otra categoría de restos cuya lista encabezan, por razones de peso historiográfico, los famosos "cráneos-copa" del Paleolítico Superior.

\section{Ejemplos de conversión de huesos humanos en útiles durante la Prehistoria}

Le Mort (1982) y Camps-Fabrer (1993), que han sido los últimos en interesarse por el trabajo de huesos humanos, concluyen que, en lo que concierne al Paleolítico, suele tratarse de piezas esqueléticas sólo levemente modificadas y regularizadas para su utilización formal como adornos. Vendría a ser el caso de ciertos incisivos de Bedeilhac, de los frontales y parietales de Veyrier o Rochereuil, de los controvertidos "rodetes" de Istúriz, o de una no menos célebre mandíbula infantil de Les Trois Frères que, para dejar las cosas claras, cuentan invariablemente con orificios de suspensión. Sólo en los cráneos-copa de Le Placard (Breuil y Obermaier 1909), pese a su falta de estanqueidad, cabría reconocer una verdadera dimensión instrumental -se dice sirvieron como recipientes para contener ocre- lo que, sin duda, representaría no una alternativa sino un complemento a la condición de talismán que se adivina en las demás piezas.

Durante el Neolítico, la multiplicación de restos esqueléticos humanos, directamente relacionada con la normalización de los cementerios, se traduce en un lógico aumento del número de huesos con huellas de manipulación, entre los que predominan aquellos con estrías y cortes de descuartizamiento. El ejemplo mejor conocido es el ya citado de la cueva de Fontbregoua, pero a él se han ido sumando en los últimos años multitud de testimonios comparables, inclusive de la Península Ibérica (Botella et alii 1997 y 1999), que no se duda en relacionar con prácticas de canibalismo, sin apenas sopesar, con Russell (1987), que en algunas ocasiones los cadáveres pudieron haber sido descarnados con la sola intención de enterrar por separado osamentas y tejidos blandos. 
Mas no es esta la clase de alteración que aquí nos interesa, sino aquella otra de mayor calado que, como sucedería en la ofrenda de Simancas, logra convertir al hueso en herramienta o adorno, en un objeto elaborado en el que late una intención funcional, decorativa o ritual, esto es, un significado añadido al de simple despojo fúnebre. El listado que de tales piezas aporta Camps-Fabrer, bastante más cumplido que el disponible para el Paleolítico, no deja de referirse predominantemente, sin embargo, a adornos o amuletos, en vez de a auténticas herramientas, entre los que hay que destacar decenas de rodetes -muy comunes en las galerías cubiertas de la Civilización del S.O.M.- que no son sino el producto de las trepanaciones craneales que con tanta asiduidad se efectuaron en el occidente de Europa durante el Neolítico Final y la Edad del Cobre (Camps-Fabrer 1993: 81-87). Pero rodetes, al fin y al cabo, con los inevitables orificios de suspensión, que revelan el mismo uso como colgantes que se adjudica a unas cuantas falanges y huesos largos -fémures procedentes, una vez más, de los hipogeos de la región de Paris (Bailloud 1964: 317) o de yacimientos italianos ya de la Edad del Bronce (Camps-Fabrer 1993: 94)- igualmente perforados.

Por contra, los testimonios conocidos de transformación de huesos humanos en útiles o armas son contados. La relación incluye varios puñales - ¿husos? (Guilaine 1972: 66)- sobre fíbula y ulna, como el italiano de Grotta Pollera, el suizo de Hauterive, y los franceses de Ganties, Tuteil y Bedeilhac; un potente punzón sobre húmero de Saint-Hippolyte-du-Fort, en el Sur de Francia, o un curioso rodillo de Castellari de Valerana -se discute si mango, instrumento de curtido de pieles o patín para hielo- al parecer elaborado a partir de la diáfisis serrada de un fémur (Camps-Fabrer 1993: 87-102). A ellos habría de sumarse alguna "copa" craneana, como la granadina de la cueva de La Carigüela, asociada a un contexto neolítico (García y Carrasco 1981). En cualquier caso, una lista demasiado exigua para apostar llanamente por su representatividad y para confiar a ojos cerrados en la competencia de los prehistoriadores a la hora de identificar el origen de los soportes de cualquier industria osea; pero también excesivamente escuálida para aceptar sin más la idea de Camps-Fabrer $(1993,108)$ de que, exceptuados los cráneos, los artesanos prehistóricos hicieron uso libremente del resto de los huesos humanos -muy especialmente de los largos- como materia prima.

\section{Algunos anclajes para la valoración del significado de nuestra espátula}

La única posibilidad de progresar en la búsqueda de información sobre este esquivo aspecto nos lleva a analizar los contextos en que se hallan normalmente este tipo de objetos. Sólo allí podrá alcanzar algún sentido el interrogatorio sobre el significado de los ídolos-espátula o sobre las particulares razones que pudieron aconsejar la labra de la pieza de Los Zumacales a partir de un radio humano. Y, aún así, como veremos, los frutos de la pesquisa serán muy limitados, reduciéndose a poco más que una serie de enunciados:

1.- Los ídolos-espátula de tipo San Martín-El Miradero se relacionan sistemáticamente con contextos sepulcrales. Del medio centenar de ejemplares conocidos, todos menos uno-el de Tagarabuena, en Zamora, hallado en prospección de superficie (Palomino 1989: 183)- proceden de osarios colectivos de la cuenca del Duero y del alto Ebro. Su dimensión funeraria es por tanto, evidente.

2.- Al margen de la posible componente utilitaria de estos objetos (varias veces se ha dicho pudieran haber servido para esparcir el ocre en las tumbas, por aparecer teñidos parcialmente con esta sustancia los ejemplares de San Martín y La Velilla o el mismo de Los Zumacales, pero hay un poderoso argumento para dudar de ello: idéntica tinción muestran la casi totalidad de los huesos de los calavernarios), la labra de sus mangos responde a una intención que trasciende el ámbito puramente decorativo: reproduce reiteradamente la iconografía -muy explícita y realista en una pieza de La Velilla (Delibes y Zapatero 1995: 339), y más esquemática, pero con representaciones sexuales concluyentes, en otras- de una mujer en la que Maluquer (1974: 89) no duda en ver la diosa de la vida y de la muerte a la que con tanta frecuencia se invoca 
en el mundo megalítico occidental. En nuestro caso, el hecho de que el icono se vincule sistemáticamente al mundo funerario refuerza no poco su consideración como imagen religiosa, como ídolo, superando las dudas que razonablemente llegan a suscitar otras figuras de rasgos antropomorfos ("ginemorfas") localizadas en sectores productivos de espacios domésticos (Nocete et alii 1998: 102).

3.- No debe descartarse que el soporte de algún otro de los ídolos-espátula conocidos sea también hueso humano, pero en su gran mayoría se consideran labrados a partir de tibias de ovicaprinos (Mújika 1998: 122-124). La de Los Zumacales es, de momento, excepcional lo que no significa -esta es nuestra opiniónque el recurso a dicho material pueda considerarse aleatorio: se puede dudar de si fue trabajada sobre hueso fresco o sobre hueso seco (en este último caso sería lógico suponer que a partir de un radio sustraído del propio osario colectivo en que se halló), pero en uno u otro caso no es fácil que interviniera el azar en la selección del soporte ni que quien se responsabilizó de su elaboración fuera ajeno a la naturaleza humana del mismo.

4.- La hipótesis, contemplada con frecuencia a propósito de los cráneos paleolíticos y mesolíticos, de que pudiera tratarse de un "trofeo", como se entienden éstos entre los "cazadores de cabezas"-una forma de apropiación simbólica del mana o de cierta cualidad de un enemigo, que exige su muerte (Wernert 1936), la cual parece existió también en el Neolítico (Bouville 1982: 38)-, pierde credibilidad desde el momento en que el escenario para su exhibición no es el ámbito de los vivos. Cabe, bien es cierto, que el trofeo, convertido en ajuar, pasara con el tiempo a acompañar a su propietario en la tumba, mas, entonces ¿qué sentido reservar al resto de las espátulas, trabajadas sobre huesos de oveja?

5.- Situándonos, por último, más en el terreno de la corazonada que de la hipótesis, propendemos a ver en las espátulas tipo San Martín-El Miradero instrumentos sagrados de uso restringido al ritual funerario $\mathrm{y}$, en la de Los Zumacales, el valor complementario de haberse sustanciado sobre los restos de un antepasado mítico, reduplicando así tanto el valor de la propia reliquia como el de las ceremonias en las que estaba llamada a intervenir.

\section{BIBLIOGRAFÍA}

ANDRÉS, M.T. (1998): Colectivismo funerario neo-eneolítico. Aproximación metodológica sobre datos de la cuenca alta y media del Ebro, Institución Fernando El Católico, Zaragoza.

APELLÁNIZ, J.M. (1962): "La falange grabada del dolmen de Gúrpide Norte", Anuario de Eusko-Folklore XIX: 227-235.

BAILLOUD, G. (1964): Le Néolithique dans le Bassin Parisien, IIme Supplement de Gallia Préhistoire, CNRS, Paris.

BARANDIARÁN, J. M. y FERNÁNDEZ MEDRANO, D. (1964): "Excavación del dolmen de San Martín (Laguardia)", Boletín de la Institución "Sancho El Sabio", VIII, 1-2: 41-66. Vitoria.

BELLO, J.M. (1994): "Grabados, pinturas e ídolos en Dombate. ¿Grupo Viseu o grupo Noroccidental? Aspectos taxonómicos y cronológicos", Actas do Seminario O Megalitismo no Centro de Portugal, Mangualde, 1992, Centro de Estudios Prehistoricos da Beira Alta: 287-304, Viseu.

BOTELLA, M.; ALEMÁN, I. y JIMÉNEZ, S.A.(1999): Los huesos humanos. Manipulación y alteraciones, Ed. Bellaterra, Barcelona.

BOTELLA, M.; JIMÉNEZ, S.A.; ALEMÁN, I.; SOUICH, Ph y GARCÍA, C. (1997): "Evidencias de canibalismo en el Neolítico español", Actas del X Congreso de la Sociedad Española de Antropología Biológica: 421-436, León. 
BOUVILLE, C. (1982): "Mort violente. Les massacres", Histoire et Archéologie. Les dossiers (La Mort dans la Préhistoire) n” 60: 36-41, Paris.

BRADLEY, R. (1998): The significance of monuments. On the shaping of human experience in Neolithic and Bronze Age Europe, Routledge, London.

BREUIL, H. y OBERMAIER, H. (1909): “Crânes préhistoriques façonnés en coups”, L'Anthropologie XX: 523-530.

CAMPS-FABRER, H. (1993): "L'emploi d'ossements humains durant 1’Holocene sur le partour de la Mediterranée occidentale et dans les pays voisins", Préhistoire et Anthropologie Mediterranéennes: $65-117$.

CAUWE, N. (1998): "Les morts en mouvement. Essaie sur l'origine des rites funeraires mégalithiques", en RODRÍGUEZ CASAL, A. (ed.) O Neolítico Atlántico e as Orixes do Megalitismo, Actas do Coloquio Internacional: 719-738, Santiago de Compostela.

CAUWE, N. (1999): “À propos des sepultures collectives dans le group de Montbolo", II Congrés del Neolitic a la Peninsula Iberica, SAGVNTVM-PLAV, Extra 2: 453-459, Valencia.

DELIBES, G. (1995): "Ritos funerarios, demografía y estructura social entre las comunidades neolíticas de la Submeseta Norte", en FÁBREGAS, R.; PÉREZ, F. y FERNÁNDEZ, C. (Coords.) Arqueoloxia da Mort na Peninsula Iberica desde as orixes ata o Medievo 61-94, Biblioteca Limiá, Xinzo de Limia:.

DELIBES, G. (1998): "Monumentos megalíticos y ritual funerario: algunas claves para su estudio", en Discursos de entrada de los Miembros de Número de la Institución Gran Duque de Alba: 43-52, Diputación Provincial, Ávila.

DELIBES, G.; ALONSO, M. y GALVÁN, R. (1986): "El Miradero: un enterramiento colectivo tardoneolítico de Villanueva de los Caballeros (Valladolid)", en Estudios en Homenaje al Dr. Don Antonio Beltrán Martínez: 227-236, Universidad de Zaragoza, Zaragoza.

DELIBES, G.; ALONSO, M. y ROJO, M. (1987): "Los sepulcros colectivos del Duero Medio y Las Loras, y su conexión con el foco dolménico riojano", en El Megalitismo en la Península Ibérica: 145-164, Ministerio de Cultura, Madrid.

DELIBES, G.; BENET, N.; PÉREZ, R. y ZAPATERO, P. (1997): “De la tumba dolménica como referente territorial al poblado estable: notas sobre el hábitat y las formas de vida de las comunidades megalíticas en la Submeseta Norte", en RODRÍGUEZ CASAL, A. O Neolitico Atlántico e as Orixes do Megalitismo: 779-808, Actas do Coloquio Internacional, Santiago de Compostela.

DELIBES, G.; ESTREMERA, M.S. y ALONSO, O. (1999): “¿Sepultura o reliquia? A propósito de un cráneo hallado en ambiente habitacional en la Cueva de La Vaquera (Segovia)", II Congrés del neolitic a la Península Ibérica, SAGVNTVM-PLAV, Extra II: 429-434, Valencia.

DELIBES, G.; ROJO, M. y SANZ, C. (1986): "Dólmenes de Sedano. II. El sepulcro de corredor de Las Arnillas (Moradillo de Sedano, Burgos)", Noticiario Arqueológico Hispano. Prehistoria 14: 7-41, Madrid.

DELIBES, G. y ZAPATERO, P. (1995): "De lugar de habitación a sepulcro monumental: una reflexión sobre la trayectoria del yacimiento neolítico de La Velilla, en Osorno(Palencia)", I Congrés del Neolitic a la Península Ibérica, (Gavá 1995), Rubricatvm 1: 337-345.

GARCÍA SÁNCHEZ, M. y CARRASCO RUS, J. (1981): "Cráneo-copa eneolítico de la cueva de La Carigüela de Pínar (Granada)", Zephyrus XXXII-XXXIII: 121-131.

GUILAINE, J. (1972): L’Age du Bronze en Languedoc Occidental, Roussillon, Ariège, Mémoires de la Societé Préhistorique Fraçaise, $n^{\circ}$ 9, Paris.

LE MORT, F. (1982): "Actions intentionelles sur les os humaines", Histoire et Archéologie. Les dossiers (La Mort dans la Préhistoire) $\mathrm{n}^{\circ}$ 66: 28-32, Paris.

MALUQUER DE MOTES, J. (1974): "En torno a la cultura megalítica de la Rioja Alavesa", Estudios de Arqueología Alavesa 5: 83-90.

MASSET, C. (1993): Les dolmens. Sociétés Néolithiques et Practiques Funéraires, Errance, Paris. 
MÚJIKA, J.A. (1998): “Ídolos-espátulas del País Vasco: fabricación, cronología y paralelos”, Veleia, 15: $121-144$

NOCETE, F.; ESCALERA, P.; LINARES, J.A.; LIZCANO, R.; ORIHUELA, A.; OTERO, R.; ROMERO, J.C. y SÁEZ, R. (1998): "Estudio del material arqueológico de la Primera Campaña del yacimiento de Cabezo Juré (Alosno, Huelva). Proyecto Odiel”, Anuario de Arqueología Andaluza 1994, II: 93-104.

PALOMINO, A. (1989): "Las manifestaciones tumulares no megalíticas del centro de la Meseta. Nuevas aportaciones en la Provincia de Zamora", Anuario del Instituto de Estudios Zamoranos Florián de Ocampo 1989: 181-191.

RUSSELL, M. (1987): "Mortuary practices at the Krapina Neandertal site", American Journal of Physical Anthropology 72: 381-397.

SAMPEDRO, C. (1998): Estudio antropológico de los restos procedentes del sepulcro de Los Zumacales de Simancas (Valladolid), Madrid, mecanografiado.

SANTIAGO PARDO, J. (1991): Informe sobre las excavaciones del dolmen de Los Zumacales (Simancas, Valladolid), Valladolid, mecanografiado.

VILLA, P.; COURTIN, J.; HELMER, D.; SHIPMAN, P. y MAHIEU, E. (1986): “Un cas de cannibalisme au Néolithique. Boucherie et rejet de restes humaines et animaux dans la grotte de Fontbregoua à Salernes (Var)", Gallia Prehistoire XXIX, 1: 143-171.

WERNERT, P. (1936): "L'Anthropophagie rituelle et la chasse aux têtes aux époques actuelle el Paléolithique", L'Anthropologie 46: 33-43. 

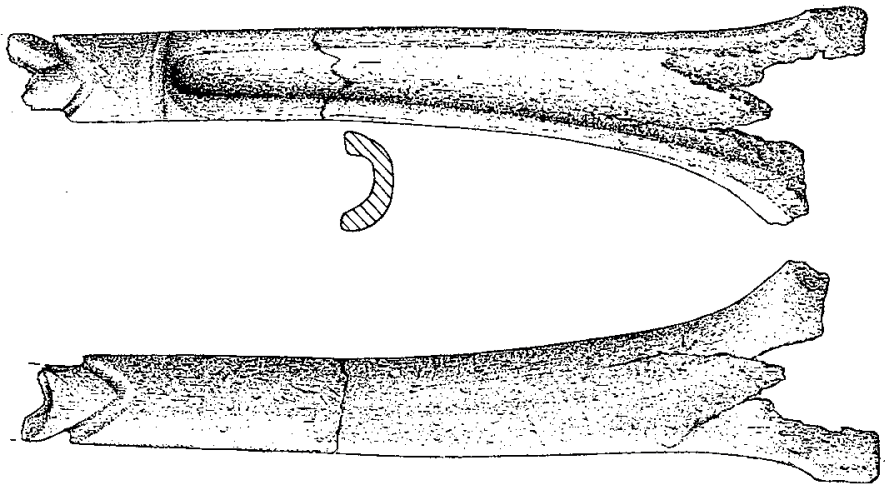

$\infty$
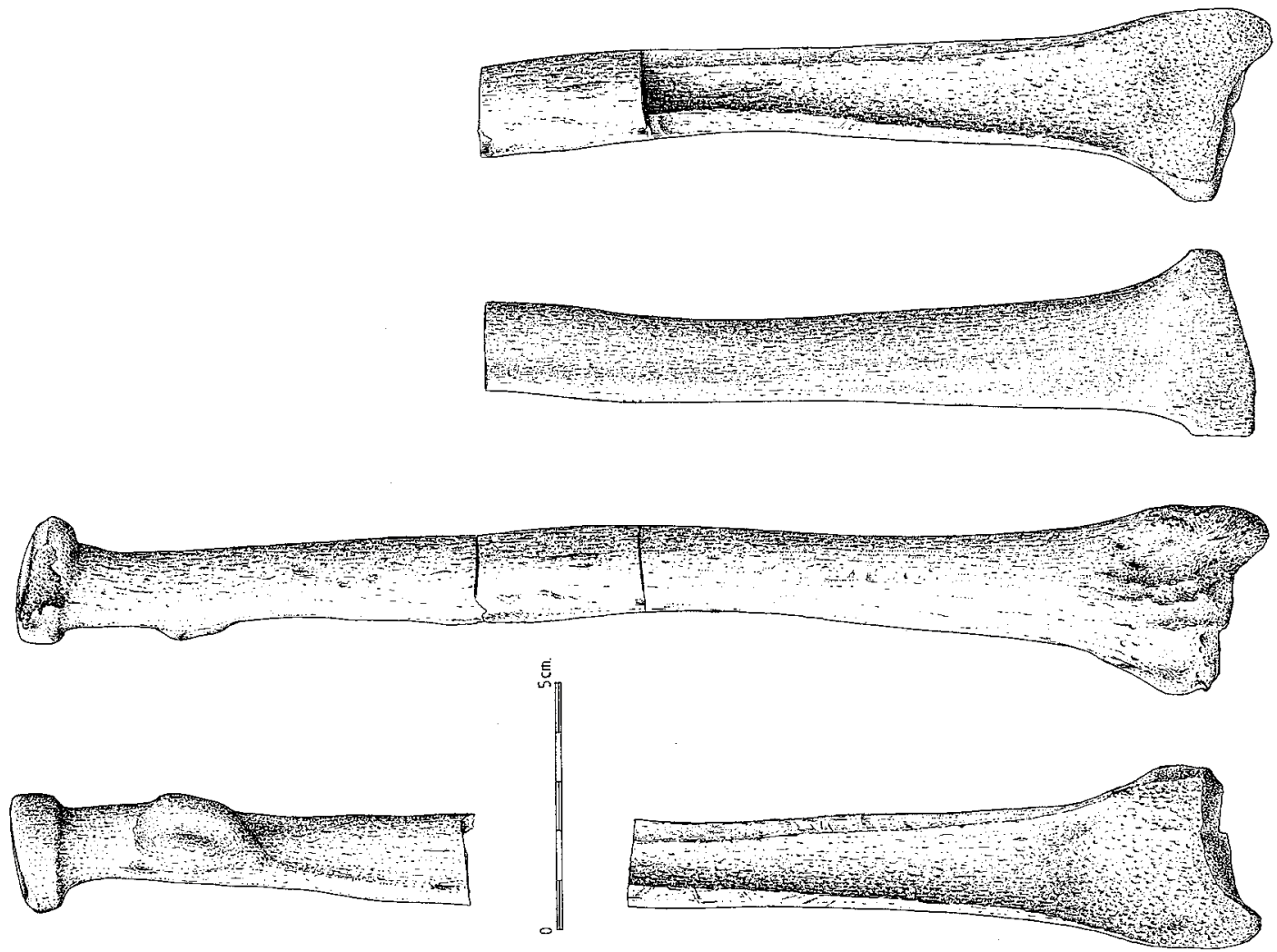